\title{
Puntos de encuentro de las mujeres en el Madrid del siglo XIX
}

\author{
CARMEN SimÓN PALMER \\ Departamento de Literatura Española \\ CSIC, Madrid
}

Si las madrileñas de la clase media habían iniciado, en el siglo xviII, su incorporación a la vida pública a través de su labor en la Sociedad Económica Matritense, será ya en la centuria siguiente cuando su presencia se haga más general y, sobre todo, más diversa.

Las peculiaridades que otorga el hecho de la capitalidad a Madrid, con aspectos positivos y negativos, condiciona la actividad de estas mujeres que tendrán en algunos casos intereses distintos a los de las campesinas, e incluso a los de ciudades pequeñas.

La elevada inmigración de personas sin ninguna especialización que recibe Madrid de otras provincias en la segunda mitad del siglo, tras la inauguración del ferrocarril y la instalación de algunas industrias, como la del gas, va a ocasionar un elevado paro y la miseria de muchas familias. Son las hijas de estos trabajadores, que ni siquiera podrán acudir a la escuela municipal, las que, si tienen alguna desgracia familiar, acabarán en algún centro de beneficencia o abandonadas en la Inclusa, de donde pasarán al colegio de la Paz, si consiguen sobrevivir.

El cambio que se opera en la capital a lo largo del siglo en lo referido al urbanismo, impulsa la creación de locales donde la relación tendrá lugares específicos, recordemos los nuevos teatros que se construyen por iniciativa privada: Comedia, Lara, Zarzuela, reservados a un determinado sector de público, en muchos casos elitista, como sucede con el teatro Real, de financiación pública. Mientras, las mujeres del pueblo se reúnen para divertirse al aire libre, en espacios abiertos, en los patios de las corralas o en las verbenas.

Desde el nacimiento, a pesar de la identidad sexual hay una diferencia de clase, especialmente llamativa. Inicialmente en este siglo aún se considera que la educación de las niñas es una cuestión privada y que se relaciona más con la moral que con la instrucción. Así, la aristocracia tiene preceptores y en la clase media la niña, en el mejor de los casos, entablará en los colegios sus primeras relaciones extrafamiliares. En épo- 
cas anteriores a 1800 no abundaron los centros consagrados a la educación de la mujer y estuvieron en manos de órdenes religiosas que continuaron luego con gran prestigio su labor en colegios como el Loreto, Santa Isabel o del Refugio. En el XIx la enseñanza femenina será fruto de la iniciativa privada, se limitará a las labores del hogar especialmente, y estará a cargo de señoras que han tenido casa de educación en provincias con anterioridad, maestras de niñas aprobadas por la Junta Inspectora y especialmente por señoras que se han educado en Francia. En la primer mitad de siglo sólo aparecen dos hombres directores de centros femeninos, uno es el fundador de las Escuelas Lancasterianas en España, Juan Kearney, que no será bien visto por los inspectores (Simón 1972). Todo es femenino en ese espacio, salvo la figura del sacerdote y la del dentista. Se advierte de las desventajas de acudir como externas, porque "para mirar por su recato" es preciso que hagan los cuatro viajes acompañadas y no siempre está garantizada la calidad moral del servicio. El objeto de la educación, advierten las empresarias, "será formar el corazón de sus discípulas, haciéndolas conocer y amar los principios de la Religión cristiana y la práctica de todas las virtudes que son base de la buena educación y prometen la felicidad para el resto de la vida" ${ }^{1}$ (Simón 1972: 305).

La educación pública femenina se acepta sólo para paliar las deficiencias morales de las familias de la clase baja y siempre bajo el principio de la necesidad de educación moral. La Ley de 1857 obliga a escolarizar a las niñas pero como educación, no instrucción, diferenciada de la de los varones (Ballarín 1993: 598-611). La evolución en las ideas, tras la revolución de 1868, y el impulso de los krausistas conseguirán los primeros avances que las permitirá poco a poco incorporarse a algunas profesiones fuera de las tradicionales, sin alejarse del modelo burgués. Se crean escuelas profesionales: de Institutrices (1870), de Comercio (1878-1879), de Correos y Telégrafos (1883), Curso de Bibliotecarias y Archiveras (1894).

Aún en estas fechas una mujer no suele salir sola a la calle, salvo si es de la clase trabajadora, y las reuniones sociales serán siempre mixtas. La burguesía sigue la costumbre de recibir visitas en unos determinados días, lo que obliga a anotar las fechas de cada conocido para no equivocarse y ser inoportuno. Dentro de las tertulias más renombradas algunas estarán presididas por mujeres, unas veces aristócratas - duquesa de Medinaceli-, otras escritoras como Pilar Sinués, Pardo Bazán, Casanova o Gimeno de Flaquer. Las primeras, con mayores medios económicos, añadirán a la charla el aliciente de poder, dada la amplitud de sus palacios, ofrecer bailes de sociedad e incluso tener teatros propios, para los que

\footnotetext{
${ }^{1}$ Colegio de doña Rafaela Felequia, año 1820. Ver Simón, 1972.
} 
escribirán autores famosos, como es el caso del de la duquesa de la Torre y Ventura de la Vega, por ejemplo.

No faltan tertulias femeninas con cierto matiz político como la que mantiene la Marquesa de Alcañices - Sofía Troubezskoy- en su palacio, donde persigue la restauración de la monarquía en la figura de Alfonso XII, en oposición a la de la duquesa de la Torre, partidaria de los Saboya. Pero estas mujeres, con medios económicos, servicio, y sin nada en que ocupar el día van a sentir la necesidad, que hacen ver especialmente sus directores espirituales, de llenar su tiempo en algo provechoso para el espíritu.

Si se observan detenidamente las asociaciones femeninas que existieron en Madrid a lo largo del siglo se aprecia una evolución paralela a la ideológica. Es decir, en un primer momento lo que prima es una relación protectora donde el pobre acepta su papel y la dama ejercerá con él la caridad cristiana. Así cumple su misión y a la vez se evitan las posibles protestas y mantiene el orden. La ley de Beneficencia de 20 de junio de 1849 en su artículo 12 aconseja a las Juntas Provinciales que se auxilien de las Juntas de señoras. Por eso se encarga a la nobleza y a los sectores burgueses llevar a la práctica esta labor, y se puede apreciar cómo por una parte funciona la beneficencia pública y por otra, grupos de señoras ejercerán la privada, entrando en competencia entre sí en muchas ocasiones.

Las asociaciones de beneficencia rivalizan y se excluyen unas a otras como parte de las luchas políticas, con el consiguiente perjuicio en su labor. Tras la revolución de 1868 aparecen las primeras sociedades más enfocadas hacia la educación con algo de instrucción, ya con la finalidad de dar un medio de vida a la mujer. Fernando de Castro proclama que la caridad es universal y el amor del hombre por el hombre en su discurso en la Universidad Central el 11 de febrero de 1869. Aquel año crearía la "Asociación para la enseñanza popular" y las "Conferencias Dominicales" que buscaban la moralización de los pobres por la educación, de las que aquí no nos ocuparemos porque estaban dirigidas por hombres en su mayoría.

Las reformas de 1873 y abril de 1875 llevaron a la separación de competencias entre lo oficial y lo privado y los liberales mantuvieron, como hizo Concepción Arenal, que la reforma social debía llegar desde la sociedad civil. La Junta de señoras, establecida por Real Orden de 27 de abril de 1875 tiene como objeto "auxiliar al Gobierno en los servicios de beneficencia, avivando la caridad y ordenando sus recursos en beneficio público" y son algunas de sus funciones las de: 
- visitar las asociaciones y establecimientos benéficos de esta Corte, estudiar sus necesidades, e invocando el auxilio de la caridad, aplicar el oportuno alivio o remedio, o acudir en demanda de él a mi Gobierno.

- cuidar especialmente de la Inclusa y de los colegios de niñas, hospitales de mujeres, casas de recogimiento y demás institutos benéficos dedicados a la instrucción, alivio o socorro de la mujer.

- Se comunicará directamente con todas las Juntas y Asociaciones de Señoras dedicadas a ejercer la beneficencia en cualquiera de sus múltiples manifestaciones e inspeccionará y organizará sus servicios para el bien común ( $\mathrm{La} \mathrm{Voz} \mathrm{de} \mathrm{la} \mathrm{Caridad} \mathrm{1875).}$

El recelo de las agrupaciones puramente católicas hacia aquellas de las que se sospecha una desviación religiosa será palpable, y llevará a las dirigentes díscolas a hacer continuas protestas de su ortodoxia. A finales de siglo, el peligro de que los movimientos revolucionarios atraigan al sector obrero impulsa la creación de reuniones católicas con finalidad religiosa e instructiva.

El asociacionismo femenino madrileño guarda una diferencia notable con Cataluña y es que allí pronto manifiestan su sentido práctico, algo que tardará años en extenderse al resto de la Península, con la creación de compañías de seguros mutuos y mutualidades para mujeres, que mediante una cuota las protegen en caso de enfermedad o viudedad.

\section{ASOCIACIONES DE BENEFICENCIA}

Varias mujeres destacan en el siglo XIX, entre las que se relacionan de algún modo con agrupaciones femeninas. Por el lado de la aristocracia: la duquesa Viuda de Gor, que impulsa y preside las principales sociedades de caridad y la vizcondesa de Jorbalán, creadora del primer centro para la reforma de las prostitutas de la Corte. Por el de la clase media, la figura de Concepción Arenal, que comienza por crear la rama femenina de las Conferencias de San Vicente de Paul e irá evolucionando con los años hacia agrupaciones de fines más estrictamente sociales, como la Cruz Roja. La Reina, y luego las infantas, apoyaron con su presencia e incluso con sus donativos algunas de las fundaciones madrileñas. Por regla general las sociedades dividían su trabajo entre las principales parroquias, y de cada zona se encargaba una señora. Anualmente la presidenta de la Junta Central presentaban la memoria de sus actividades.

En una ciudad donde las necesidades son grandes, las ocupaciones caritativas son variadas. A principios del siglo xIX, casi todos los centros 
benéficos de patronato regio fueron relevados por Carlos IV de la tutela del Consejo de Castilla, para ser dirigidos por juntas de nobles ilustradas. En 1799 la Real Junta de Damas de Honor y Mérito, creada en 1787 y dependiente de la Sociedad Económica Matritense, fue encargada de la dirección de la Inclusa (fundada en 1567) y siete años después de la del Colegio de la Paz. La labor que desplegaron para mejorar la calidad de vida de la Inclusa fue intensa, contrataron un segundo médico, organizaron una enfermería y ese mismo año de 1800 incorporaron al servicio de la institución a las Hermanas de la Caridad. A partir de 1820 se encargaron de visitar directamente a los niños que criaban las nodrizas externas en los barrios pobres de Madrid. En 1807, tras varias mudanzas, la Inclusa fue trasladada a la calle de Embajadores, a un edificio a espaldas del Colegio de la Paz y comunicada con él por una puerta interior. La economía, pese a las ayudas de la Corona, fue siempre deficitaria. Al llegar los gobiernos liberales la situación empeoraba por la idea de que la Beneficencia debía estar a cargo del Estado. Pretendieron ser financiadas por la Administración, sin éxito. La vuelta de la monarquía absoluta supuso la continuación de su labor hasta que en 1839 se rompen las relaciones entre el municipio y la Junta, a raíz de la diferencia de criterios a la hora de nombrar el nuevo rector del centro. El 9 de octubre de 1840 la duquesa de Gor entrega toda la documentación a la Junta Municipal de Beneficencia y en los años siguientes recibió múltiples ataques la labor de las Damas, pero lo cierto es que al pasar a ser responsabilidad de la Diputación en 1849, las señoras de la Junta fueron repuestas en la dirección de ambos centros (Vidal 1998: 57-72).

Los primeros años del XIX estuvo al frente la condesa-duquesa de Benavente, María Josefa Alonso Pimentel, y la sucedió hasta su muerte, María Carmen Chacón Carrillo de Albornoz, duquesa Viuda de Gor. En 1880 la preside la entonces Princesa de Asturias, Isabel, por lo que las reuniones se celebran en Palacio. Para allegar fondos organizan funciones de teatro, bailes de sociedad y conciertos en el Buen Retiro. La prensa se hace eco de todas las acciones caritativas de la Junta de Damas, como el socorro de tres pesetas, dado en un caso de miseria a un señor mal vestido, "pero de buenos modales" que vivía en una cueva del barrio de Salamanca con sus hijos, que estaban desnudos.

La labor más conocida es la que realizan al frente de la Inclusa y el Colegio de la Paz, cuya capilla continúa aún hoy en pie en la calle de doctor Esquerdo. Es ilustrativo el lenguaje empleado en sus informes por la Duquesa al tratar de la mortalidad infantil, porque los niños no mueren sino que "ganan o pierden en conservación", y así habla de éxito porque ese año de 1840 están en el $12 \%$ de bajas, frente al $39 \%$ del 
anterior. En total había entonces la enorme cifra de 2.116 personas en la Inclusa, de ellas 1728 niños entre los de dentro y fuera, 60 amas dentro, 23 Hermanas de la Caridad y 305 niños de más de siete años.

En cuanto al colegio de niñas, a cargo de las Hermanas de la Caridad, seguía el reglamento fijado en las Ordenanzas de la Orden, verdaderamente duro. Con las labores que realizaban contribuían al sostenimiento del centro.

El año 1800, la condesa viuda de Lerena, marquesa de San Andrés, solicitó el permiso para fundar un hospital dedicado al cuidado de las ancianas impedidas o afectadas de enfermedades consideradas incurables, como parálisis y "chochez". Conseguido el permiso, se instaló el año 1803 en la calle de Conde Duque, esquina a la de Limón, el Hospital de Jesús Nazareno, al que se conocería como "de incurables". En 1824 el Rey les cede la casa del conde de Monterrey en la calle de Amaniel 11. La condesa reunió un grupo de señoras para cuidar y gobernar el centro. El hospital de pobres vergonzantes e impedidas debía mantenerse sólo de limosnas que las Damas Tutoras recogían de puerta en puerta, y cada año permitían la entrada pública un día (13 de abril 1833), aunque siempre tuvieron problemas de financiación. En principio estaba prevista la fundación de un congregación de treinta religiosas de clausura que tendrían el noviciado en el mismo hospital, pero lo cierto es que no llegó a cuajar la idea y tuvieron que hacerse cargo de la obra las Hermanas de la Caridad. Finalmente acabó por considerarse centro público de beneficencia por los liberales en 1836 (Vidal 1993: 167-76).

La duquesa viuda de Gor fue presidenta de la Sociedad de Señoras, que estaba integrada por 83 damas de la alta sociedad y consagrada al socorro de las religiosas, tras la expulsión de 1839. Por una parte, crean centros en los que se reúnen a los necesitados, por otra entran en sus casas para calibrar cuáles son las necesidades reales y ejercer la caridad de modo directo y material.

Con la división habitual en juntas parroquiales y su correspondiente presidenta va a funcionar a lo largo de todo el siglo la Real Asociación de Beneficencia Domiciliaria de Madrid, presidida por la Reina y con la duquesa viuda de Gor de nuevo, como vicepresidenta. Las damas visitan los domicilios de los pobres de su Junta y para allegar fondos celebran conciertos en el Buen Retiro. Ya en los años 1869 la vicepresidenta es la condesa de Torrealta, Angustias Zuloaga.

Un fin bastante similar persigue la Rama femenina de las Conferencias de San Vicente de Paúl, introducidas en España por Santiago Masarnau. Concepción Arenal, a través de su amigo Jesús de Monasterio, miembro fundador de la rama masculina, intentó el año 1860 fundar la femenina y 
tuvo que luchar con el recelo que aún existía a confiar a mujeres una tarea de organización y trabajo directo con el necesitado. El objetivo era dar testimonio práctico de la fe cristiana en las casas de los pobres y en principio en España contaron con el apoyo de sectores liberales. Concepción Arenal, que acabó por convencer a Masarnau de la conveniencia de esta tarea, va a dedicar su manual El visitador del pobre a las Hijas de San Vicente de Paul, pero matizando que "no sólo a las Hermanas de la Caridad sino a todas las personas que procuran el consuelo de los pobres, siguiendo el sublime ejemplo de San Vicente de Paul, que es el espíritu del Evangelio".

El Asilo de Huérfanas de la Sagrada Familia que a finales de siglo se conocerá como "Asilo de Huérfanos del Sagrado Corazón de Jesús", lo funda, en contra de la opinión de su familia, Ernestina Manuel de Villena, hija de los marqueses de Gracia Real. Alquila un local por una peseta diaria, recoge a un huérfano $y$, con una monja, comienza una obra "con alto fin religioso, humanitario y social", que dirigirán las Hermanas de la Caridad. En 1864 lo visita el secretario del cardenal-arzobispo y le concede un oratorio, en el que podrá conservarse permanentemente la Eucaristía y, además, indulgencias a los suscriptores y bienhechores. Del primitivo edificio, reducido y reflejo del "aflictivo" estado de recursos, que sólo permitía acoger a dieciocho niños, se trasladó aquel año a otro en la calle del Casino 5, y pudo ampliar el cupo a treinta y una plazas. La fundadora persiguió a todos los poderosos durante años para conseguir fondos, pero no logró que Isabel II le concediera una asignación anual como establecimiento público de beneficencia. Habría de esperar a que su hijo Alfonso XII llegara al trono y de su bolsillo fijara como aportación anual mil pesetas. Otros ingresos provenían de las tarjetas, uinvitaciones" las llama, impresas para suscripciones y socorros, en las que figuraban los beneficios espirituales que recibirían a cambio, lo ganado del alquiler de sillas en las iglesias y paseos y de los cepillos que había situados en la propia casa y en las iglesias de San Millán, San Cayetano, Loreto, así como donativos de comestibles. Entre los gastos, aparecen los salarios de los criados, lavandera y aguador, repartidores y guardas de sillas.

La conclusión de la Memoria del año del primer traslado de domicilio, 1864, no pudo ser más optimista: "la salud, contento, docilidad y adelantos de nuestros acogidos no dejan nada que desear". Tuvo Ernestina entre sus amigos a Pedro Antonio de Alarcón que publicó en La Ilustración Española y Americana varios artículos sobre su obra con lo que consiguió donativos de España y de América. Encargó Ernestina al marqués de Cubas el proyecto del edificio que se levantaría en la calle Claudio 
Coello (manzana 208, n. ${ }^{\circ} 100$ ), en el barrio de Salamanca. El arquitecto se lo hizo gratuitamente, en diciembre de 1880 se ponía la primera piedra y seis años más tarde estaba terminada la iglesia, de estilo neogótico y fachada de ladrillo (Navascués 1973: 211-12). Llevaba la fundadora entonces más de cuatro millones invertidos y mantenía a 250 huérfanos a los que se daba un oficio, ya que en el hospicio funcionaba una importante imprenta. Durante el invierno abre al público en el mismo edificio del Corazón de Jesús, un Comedor de la Caridad, en el que las damas protectoras de este asilo ofrecen una sopa y pan a todos los pobres que se presentan. Si en el primer año se dieron siete mil socorros, en el cuarto habían pasado a cuatro mil diarios, en un horario de una de la tarde al anochecer, durante los tres meses de mayor rigor en Madrid. Acude en alguna ocasión a servir la infanta doña Eulalia. Sólo daban sopas, de las que se podía repetir, y una ración de pan. Después de la comida a los niños "Se les adoctrinaba en las prácticas de la religión, en cantos y rezos, en ideas de virtud y moralidad y hasta en actos de urbanidad y cortesía" (La Época 1891, Gimeno 1901: 200).

Pero en Madrid no sólo hay residencias externas, internas y de asistencia domiciliaria, el interés religioso de algunas damas es universal y por eso se funda, un Consejo de Señoras de Madrid de la Obra de la Santa Infancia, con sede central en París y con la Junta de Gobierno dirigida por la duquesa de Gor, como presidenta la condesa de Salvatierra y juntas parroquiales con sus correspondientes presidentas.

La Orden de Predicadores de Santo Domingo de Guzmán estaba encargada de la salvación de los cuerpos y las almas de los niños de Tongkin y China. Gracias a las limosnas recogidas en Madrid en 1854 se bautizaron en Tongkin 22.809 hijos de infieles en artículo de muerte, de los que sobrevivieron 1007. Por eso la presidenta declara: "Hemos llevado al cielo en un año 21.800 angelitos que incesantemente clamarán ante el trono de Dios en nuestro favor". Estos niños, añade la condesa de Salvatierra en su Memoria, "tuvieron la desgracia de no tener padres sino infanticidas porque si conservan a sus hijos los educan en la gentilidad y les quitan la felicidad eterna" (Memoria 1856).

Se da la oportunidad a los benefactores de que sugieran nombres, que luego se adjudican por sorteo a los infantes "rescatados", en una función celebrada en la iglesia de Nuestra Señora de Atocha y, como no puede ser de otra manera, se presenta a la cabeza la Princesa de Asturias, de cuatro años y protectora de la obra. Según el estadillo final de la Memoria, la población católica era aquel año de 150.505 y la infiel 3.899.495, algo verdaderamente sorprendente porque da a entender que existían censos exactos de población. 
La guerra de África va a producir una serie de situaciones desastrosas en aquellos que regresan del frente, pobres y sin trabajo. Se organiza la comisión presidida por la marquesa de Miraflores, el año 1876, para el recibimiento triunfal del Rey y generales que le acompañan, con una corona, un arco en la calle de Alcalá y diecisiete misas en San Ginés y el Espíritu Santo, pero también cada dama dará cuarenta bonos a los soldados pobres.

Se carecía de una asociación que ayudara a los pobres en la hora de la muerte. Se le ocurrió a D. José María Dalmau y obtuvo el permiso del Gobierno para fundar la Sociedad llamada La Estrella de los Pobres (Estrella 1875) y celebrar rifas periódicas en unión con la Lotería Nacional, con el objeto de allegar fondos. Pero al morir repentinamente, la Junta de señoras y el secretario general, D. Eugenio de Capitani, continuaron su labor y elaboraron los estatutos. Se inauguró en octubre de 1873 y la secretaria, afirma entonces: "La misión de nuestro sexo en la tierra no es otra que el amor, la paz y la caridad, sobre todo la caridad cristiana". Hay que destacar aquí que esta señora, Sofía Tartilán, conocida escritora, figurará años después en las filas de la masonería, colaborando también en "Las dominicales del librepensamientom. Se nombra Director General de la Asociación a D. Francisco de Paula Méndez, Patriarca de las Indias, lo que le da un carácter católico, y resalta Tartilán: “rechazando de este modo las injustas sospechas que se propalaron al principio sobre el espíritu religioso de nuestra Asociación" (La Estrella 1875: 5). La Patrona es la Santísima Concepción con un medalla como distintivo de la señoras.

Asisten en los gastos de los entierros, en la Memoria se da cuenta de las mortajas y ataúdes costeados, y disponen ya de un coche fúnebre al año de su creación. La presidenta del Distrito del Hospicio, Antonia de Ochoa, ha conseguido dos beneficios en los jardines del Retiro y Plaza de Oriente. El periódico La ilustración de la Mujer, dirigido por Sofía Tartilán, es el órgano de la Asociación y en él da cuenta de la labor y los elevados gastos, así como del deseo de crear una escuela de niñas pobres.

\section{ASOCIACIONES EDUCATIVAS}

No pretendemos aquí hacer un estudio de los centros de enseñanza, tan sólo mencionar algunas asociaciones creadas por señoras, pero inspiradas por la Iglesia Católica de un lado y por el sector de los hombres liberales de la Institución Libre de Enseñanza por el otro. La finalidad en ambos casos fue atraerse a una población femenina desfavorecida por la 
fortuna y que para el sector católico corría el riesgo de ser atrapada por los incipientes movimientos revolucionarios y por los protestantes. Los krausistas, tras la revolución de 1868 impulsaron la formación de la mujer, siempre dentro de un orden, para que por el conocimiento pudiera ganarse la vida en caso de necesidad, pero lo cierto es que en la Asociación para la Enseñanza de la Mujer fueron muy escasos los puestos directivos reservados para mujeres.

La Real Sociedad de Señoras de las Escuelas Dominicales nace con el propósito de dispensar a sirvientas y jóvenes pobres una educación e instrucción cristiana, acomodada a su edad, sexo y condición. Ahora bien la instrucción se dará "en los precisos límites de leer, escribir y contar, enseñanza de Catecismo, Doctrina Cristiana para temor de Dios y aborrecimiento de vicios" porque, añaden:

Todas las personas piadosas conocen y deploran los peligros a que se ven expuestas en los días festivos las sirvientas y otras jóvenes hijas del pueblo, y se echa de menos en la capital de un reino católico como el nuestro un asilo adonde puedan retirase esas tardes, evitando así todo riesgo de perversión.

Las Escuelas pertenecen a una Junta de Señoras con miembros de dos clases: Socias de número, que enseñan y con las que se forma un Consejo de doce señoras, que se renueva cada cuatro años, y Socias de honor, que ayudan en la enseñanza o con limosnas. Hay una Junta de gobierno con presidenta, vicepresidenta, secretaria y tesorera que se reúne mensualmente para revisar cuentas, problemas y visitar las escuelas. El director espiritual perpetuo es nombrado por el Consejo. Cada quince días se hace cuestación entre las socias de número y todos los meses se cobra la cuota de suscripción. Las Escuelas dividen en grupos a las educandas según la edad, saber e inteligencia. Ni siquiera en los días de asueto se deja de dar la lección de catecismo y dos veces al año, en Navidad y por San Juan, se premia a las alumnas más aprovechadas y “de mejor proceder".

La Asociación Católica de señoras de Madrid, se crea en 1872, tras haber presentado el Reglamento la condesa de Superunda al arzobispo, quien lo aprobó, otorgando cien días de indulgencias en cada acto religioso de la Corporación. No fundan colegios sino que sostienen escuelas gratuitas para los niños y niñas pobres de Madrid (Reglamento 1872). La condición que se requiere para ser consiliaria de una escuela es que "a su discreción y virtudes, reúna, a ser posible, buena posición social. Se admiten todos los niños y niñas pobres, pero católicos, entre siete y doce años. El local, sin lujo, se buscará en paraje retirado "para que no se sienta mucho el ruido de los carruajes y transeúntes, que distrae a los niños y 
les quita la atención al estudio". Se colocará un cepillo por si alguien quiere dar algo para la escuela y en cada local un cuadro o pequeño altar dedicado a Ntro. Señor, la Purísima Concepción o a San José.

Se enseña la Doctrina Cristiana, por el Catecismo de la Diócesis, la Historia Sagrada, un Compendio de la Iglesia, la Gramática Castellana, a leer y escribir, y la Aritmética práctica proporcionada a la edad y a la posición de los niños. Por vía de estímulo, a los más aventajados, dos veces por semana, se les podía enseñar algunas nociones elementales de Geografía e Historia, principalmente de España. A las niñas a coser, zurcir, remendar y hacer calceta; y "solamente a las más virtuosas y aplicadas" a bordar y otras labores propias de su sexo. De nuevo, igual que en el Reglamento de las Hijas de la Caridad, aparecen las niñas como mano de obra gratuita, porque las señoras de la Asociación: "podían ocupar a las niñas en labores que les mandaren hacer"; y lo que voluntariamente se diere por este trabajo, se invertirá en favor de la casa matriz de las niñas o en limosnas a los padres más pobres. Cosían dos horas diarias y, mientras lo hacían, una compañera leía en voz alta.

Tras tres años de asistencia recibían una "Patente" que podía servirles "algún día" de recomendación "con tal que hayan guardado en el mundo buena conducta y una fe intachable hacia el catolicismo" (Reglamento 1872:19.). El sistema de recompensas es el habitual de "vales" y premios al final del curso y gratificaciones de fruta, pan, pieza de ropa o de calzado, medallas y estampitas. Es curioso observar la insistencia en el silencio, no sólo del local, sino también en las clases, por lo que se aconseja a los maestros que hagan cuanto puedan para suprimir las voces de mando, adoptando la claque o cualquier otro sistema convencional de signos.

Por último, el anuncio de la instalación de una capilla evangélica en la calle de la Beneficencia el año 1893, provocó el que un grupo de señoras acordara establecer dos escuelas católicas a ambos lados del templo de los disidentes: "para contrarrestar los efectos de la enseñanza de la doctrina protestante" (La Época: 3-I-1893). Antes, el día 13 del mes de enero, trataron de impedir la apertura reuniéndose allí, pero sin éxito. El 7 de febrero de 1893 celebran, en el salón del Conservatorio, organizado por la condesa de Orgaz un concierto vocal para lograr recursos para la escuela católica de San Lorenzo. El 27 de ese mismo mes, les visita la Reina regente y se inaugura oficialmente en marzo (La Época: 27-II-1893).

Creemos que la primera asociación profesional madrileña fue la Asociación de Institutrices y Profesoras de Comercio, creada por las estudiantes de la Escuela el año 1882 (Reglamento 1878), con el fin de defender la causa de la educación de la mujer y continuar la actividad de las es- 
cuelas con grupos de discusión sobre "asuntos científicos y comerciales". Se acudía a los profesores en caso de dudas graves y por escrito. El reglamento aparece en La Instrucción de la Mujer (n. ${ }^{\circ}$, marzo de 1882). Pero no tenemos constancia de que llegaran a formar, como era su propósito, una sociedad de socorros mutuos para ayudar a los miembros que tuviesen problemas económicos y encontrar trabajo a las estudiantes.

\section{ASOCIACIONES ¿MASÓNICAS?}

Hemos advertido al principio de este trabajo la estrecha vigilancia que observan los sectores católicos hacia todas aquellas agrupaciones femeninas que no están bajo la tutela de la Iglesia católica. Aunque la masonería era ya una institución con muchos siglos de existencia, cercana la fecha de la Revolución de 1868, y por diversos motivos, un elevado número de personas de la más diversa condición: intelectuales, militares, aristócratas, van a afiliarse a ella y surgen ramas femeninas paralelas. La preocupación por lo "incontrolable" es inmediata y pronto se tachará a muchas sociedades femeninas con el calificativo de "masónicas", con lo que quedan condenadas de manera automática. Trataremos aquí exclusivamente de aquellas femeninas que fueron acusadas de pertenecer a esta institución, dada su vinculación a los sectores liberales. Puede observarse la coincidencia de fines y la insistencia de algunas figuras insignes, como es el caso de Concepción Arenal por desmarcarse, aunque su nombre aparezca vinculado a casi todas, de uno u otro modo.

La Asociación Abolicionista Española se funda a fines de 1864 y oficialmente el 2 de abril de 1865, en la Academia Matritense de Jurisprudencia y Legislación, con la finalidad de hacer desaparecer la esclavitud en las colonias españolas. Pertenecen a ella Olózaga, Fermín Caballero, etc., y ya en el primer mitin que celebran en Madrid, en el teatro de Variedades el 10 de diciembre de 1865 , se incorpora a ella la Sociedad de Señoras de la Asociación Abolicionista Española, integrada por las condesa de Pomar y Priegue, y las señoras de Ayguals de Izco y de Briester Vizcarrondo, a las que se suman figuras como Concepción Arenal, Matamoros de Tornos y Faustina Sáez de Melgar.

Pilar Amandi de Ozores, condesa de Priegue, había nacido probablemente en Cuba y fallecería en La Coruña en 1909. Unos años después de este mitin fundacional de la Asociación Abolicionista, la veremos presidiendo una sociedad masónica. En cuanto a Concepción Arenal, que nunca querrá aparecer claramente vinculada a la masonería, aunque muy probablemente su padre lo había estado y ella tenía grandes amigos en 
sus filas, pronto, desde El Abolicionista Español, órgano de la Sociedad., manifiesta su desconfianza por el carácter político que se empieza a dar a la asociación, aunque participa de forma anónima con un poema que es premiado, sobre la esclavitud de los negros.

En 1872 se crea un periódico titulado Las Hijas del Sol, órgano al parecer de la logia masónica del mismo nombre. El proyecto del instituto femenino Las Hijas del Sol, se presenta al Gran Oriente de España en 1873, con estatutos redactados el año anterior. La organización prevista es similar a la llevada a cabo por Concepción Arenal en las Conferencias de San Vicente de Paul, con las "decenas", es decir: "Diez Hijas del Sol reunidas, constituirán una constelación: diez constelaciones un sistema; diez sistemas una zona y diez zonas un cielo (Boletín Oficial del Grande Oriente de España 15-octubre-1872, n. ${ }^{\circ}$ 36). Persiguen:

1) La Educación física, intelectual y moral de la mujer

2) La caridad y la beneficencia

3) La justicia

4) La protección mutua

Al tiempo, fundan un periódico con el mismo nombre, órgano de la Asociación, que preside la condesa de Priegue y que dirige, durante su estancia en Madrid, la baronesa de Wilson, Emilia Serrano, que había regresado ya de su primera visita a América en 1865, y publica en él su novela: La miseria de los ricos. Historia de dos millones. Otra ilustre escritora, Concepción Gimeno, que asimismo vivió en América, y dirigirá el Álbum ibero-americano, también participa en este grupo.

El Ateneo Artístico y Literario de Señoras va estar presidido por la escritora Faustina Sáez de Melgar, también miembro del Comité de Señoras de la Asociación Abolicionista y directora de revistas en Madrid y París. De sus muchas obras merece aquí destacarse la dirección ${ }^{2}$ de $L a s m u$ jeres españolas, americanas y lusitanas pintadas por si mismas (1885). En la Memoria publicada al año de su creación, leída en 1869, habla de los resultados grandes y sorprendentes obtenidos desde su fundación, el 28 de diciembre de 1868, porque no contaba ni con medios, ni con socias: "Sola, sin más apoyo que mi inspiración, mi firmeza y mi confianza en la

${ }^{2}$ Faustina Sáez de Melgar nació en Villamanrique de Tajo (Madrid) hacia 1834 y casó con Valentín Melgar. Perteneció al Comité de Sras de la Abolicionista. Falleció el mes de marzo de 1895. Fue directora de La Violeta, La canastilla infantil y París Charmant artistique de París. Dirigió Las mujeres españolas, americanas y lusitanas pintadas por sí mismas: Barcelona. Juan Pons (s.a. 1885) 843 p. En 1866 convoca desde La Violeta a las poetisas para ofrecer un álbum a Zorrilla que regresa de Méjico. 
bondad del pensamienton. Silencia por completo el respaldo de Fernando de Castro, su promotor tras el triunfo de la revolución de 1868, antes al contrario, deja claro que la Asociación es "Ajena por completo a la política y los partidos [...] no se asusten los espíritus tímidos que critican la fundación del Ateneo" (p. 23). Pide el apoyo de la prensa, del Gobierno y la aristocracia ilustrada "que representa la grandeza y la inteligencia". Se dirige especialmente a la clase inteligente de la sociedad a la que no se socorre con un mendrugo".

El Reglamento, publicado en La Iberia en diciembre de 1868 y enero de 1869, al plantear la instrucción para todas las clases de la sociedad con la finalidad de que, si lo necesitan, las mujeres puedan crearse un medio de vida con un trabajo digno y la moralización por el trabajo de acuerdo con la doctrina protestante de algunos sectores krausistas, suponía un cambio frente a la postura de la Iglesia católica, a pesar de no buscar otro papel para la mujer que el de esposa y madre: "Yo acato y suscribo: Junto a la cuna de mi hijo he escrito todas mis novelas ¿Cómo educarlos si no estudian?".

Se habla del deplorable atraso de la mujer en España y su necesaria reforma: "El carro majestuoso de la civilización triunfante hoy en España va indicando las sendas regeneradoras que deben recorrerse. Se comprende el peligro de la propagación de la mujer doctora y marisabidilla: "No será nunca la mujer verdaderamente instruida la que desconozca el ridículo de la mujer doctora evitando con su buen sentido tan extravagante exceso". Quiere a la mujer "Mujer ante todo: buena esposa, madre, buena hija antes que sabia" (p. 25).

Sólo se asociaron trece señoras, con las que se formó la junta de gobierno. En menos de dos meses ya había sesenta y cuatro socias de pago, otras tantas de mérito y profesoras para todas las clases, si bien el reglamento no podrá seguirse al pie de la letra porque debían compatibilizar el trabajo y las obligaciones domésticas. El Rector, Fernando de Castro, inauguró y clausuró las clases, presidió los exámenes y dio los premios. Contó con la protección de la duquesa de la Torre, que aportó 100 reales mensuales y consiguió que el Ministro de Fomento les cediera la escuela nacional hasta el 4 de mayo, cuando se necesitó. Entonces se habilitaron los salones del palco regio del Teatro de la Ópera para los exámenes. Los señores de Piquer, por su parte, cedieron su teatrito para las sesiones recreativas.

La dirección de las conferencias la llevó otra escritora, Joaquina García Balmaseda, porque la presidenta estuvo muy enferma el primer año. Se celebran por la noche, los días no festivos y, dice la presidenta: "como hay pocas mujeres ilustradas en España, se llamará a los hombres". Junto a 
alumnas, de entre 12 y 14 años, pueden asistir las socias que lo deseen. Ahora bien: "Para que las señoras no se distraigan en sus estudios está prohibida la entrada de caballeros en las cátedras diarias y en las conferencias los días no festivos. Solamente son invitados a las sesiones recreativas de los domingos los padres, maridos, hijos y hermanos de las socias".

Entre los socios que dan conferencias están los más importantes intelectuales del momento: Fernando de Castro, quien el 21 de febrero de 1869 pronunció la primera conferencia sobre la importancia del sentimiento religioso en la educación de la mujer. Proclamaba la unidad humana por encima de la división de sexos y la "personalidad racional de la mujer" basada en su semejanza con Dios. Continúan, Manuel Ibo Alfaro, Joaquín Arjona, Antonio M. ${ }^{a}$ Segovia, Fernando Corradi, Juan Valera, W. Ayguals de Izco, Ventura Ruiz Aguilera, Juan de Dios de la Rada, Rafael Labra, Campoamor. Entre las señoras: G. ${ }^{a}$ Balmaseda, Blanca Gasot (sic), Emilia Mijares de Real, Micaela Silva, Sáez de Melgar y, añaden en la Memoria: "Se leyeron artículos de Gertrudis Gómez de Avellaneda, Concepción Arenal y Angela Grassi".

Era una extensión de la enseñanza universitaria promovida por Castro desde el Rectorado de la Universidad de Madrid y Concepción Arenal asumió la tarea de corresponsal en la prensa. Diferentes aspectos fueron tratados con espíritu moderado y algo más moderno que lo habitual por los conferenciantes.

El día 7 de junio de 1870 se reunían en el palacio de Medinaceli de Madrid por invitación de D. ${ }^{a}$ Ángela Pérez de Barradas y Bernuy, duquesa de Medinaceli, las señoras más distinguidas de la capital de España. Asistía como delegado de la Asamblea Española de la Cruz Roja, Basilio Sebastián Castellanos, y tras escucharle quedó formalmente instalada la Sección de Señoras de Caridad de la Cruz Roja en España.

Si observamos la composición de las juntas de distrito y directiva vemos que sólo hay un miembro que no es de la aristocracia, junto con la secretaria general, "la ilustre escritora señora Doña Concepción Arenal" ( $M e-$ moria 1879). Las que la prensa califica como "nobles y caritativas damas", difundieron bien pronto entre todo el bello sexo de Madrid los "generosos propósitos y el levantado espíritu de neutralidad" que informaba la Cruz Roja y se prevenía que en caso de perturbación funcionaría en el palacio de Medinaceli un hospital establecido por estas señoras.

La Cruz Roja sufrió durante la guerra numerosas persecuciones desde los medios antiliberales. Concepción Arenal, en una carta a la duquesa de Medinaceli publicada en La Voz de la Caridad, le recomendaba:

[...] contra calumnia, resignación... tenemos que resignarnos a que se desconozca nuestra recta intención, a que se interpreten mal nuestras palabras, a que se ca- 
llen o se nieguen nuestras obras, a que la calumnia nos denueste y a que el error y la malicia vayan publicando nuestro descrédito. Una vez aceptado el difícil papel de calumniadas, dejando a nuestros calumniadores el suyo, fácil y desdichado, tendremos mayor tranquilidad de ánimo, dedicando al socorro de los heridos el esfuerzo que podría distraerse en una lucha inútil....llegará el día de la justicia, y si tarda, tanto peor para los que nos la niegan" (La Voz 1874).

Mantiene Arenal que el emblema de la Cruz Roja llegó a convertirse en una "señal inútil o peligrosa para el que la lleva" e hizo notar desde La Voz de la Caridad que uno de los acosos más convincentes era el de propagar que la masonería estaba detrás de la Cruz Roja. El Consultor de los Párrocos publicó tres artículos a finales de 1873 mencionando a la institución dentro de la mentalidad de la masonería. Arenal se unió a la defensa de Antonio Balbín y desde La Voz de la Caridad, no afirmó ni negó la presencia de la masonería:

La Cruz Roja abre una nueva era en las relaciones internacionales de los pueblos, es el apóstol más elocuente de la paz que un día (no queremos renunciar a esa esperanza) reinará entre ellos, y revela un gran progreso moral... con sus acciones afirma que los hombres son hermanos. con la caridad, la caridad de San Pablo que no se cansa ni mueve a ira, convenza a sus enemigos de injuria y calumnia, no ante tribunales de justicia, sino ante la conciencia, por los hechos.

En su revista, como secretaria de la institución, fue publicando una serie de cuadros de guerra y allí se puede seguir la labor en las guerras civiles desde 1872. La Presidenta ofreció su apoyo al conde de Ripalda, que lo era de la Asamblea Española y entregó gran cantidad de hilas, vendajes y efectos de curación que habían elaborado "las delicadas manos de las señoras de la Sección y sus amigas", y que se enviaron a Pamplona, Vitoria y San Sebastián. No vamos a detenernos a detallar el trabajo de todas estas damas, que desde Madrid mandaron frecuentes refuerzos, y que organizaron bailes, conciertos y numerosos actos de sociedad para recaudar fondos. Sí quisiéramos mencionar que de nuevo aparece el nombre de Emilia Serrano como medalla de oro de la Institución

A la hora de repasar las agrupaciones de mujeres, no podemos dejar de destacar dos de carácter religioso, destinadas a acoger a las prostitutas y desvalidas, que fundan por aquellos años, en contra de amplios sectores católicos de la población, dos mujeres que llegarán a ser canonizadas y que no parece que se guardaran especial simpatía, quizás por la coincidencia en los objetivos. Es la primera la Comunidad de Adoratrices Esclavas del Santísimo Sacramento, fundada en 1845 por Micaela Desmasieres, vizcondesa de Jorbalán, luego Santa María Micaela del Santísimo Sacramento, y cuya obra ha pasado a la literatura a través de la descrip- 
ción de Galdós del convento de "las Micaelas" en Fortunata y Jacinta. Las Reglas comunes [...] de las Adoratrices, publicadas en 1898 nos ofrecen una muestra de cómo reeducar a aquellas mujeres que no cumplían con las normas, y a las que se consideraba "desamparadas". Eran admitidas entre los 15 y los 25 años con la condición de "no padecer accidentes ni humor contagioso, y no tener defecto físico notable». Según su educación pasaban al grupo bajo la advocación de San Miguel: "Micaelas", más selectas, o al que estaba bajo Santa Filomena: "Filomenas". Se calculaba que tres años eran suficientes para cimentar su virtud y acostumbrarlas al trabajo en clases de cincuenta alumnas. Si había indicios de pertenecer a alguna secta eran expulsadas.

La otra gran fundación es la llevada a cabo, también con la oposición familiar, por Vicenta María López y Vicuña. Ya en 1869 tiene un piso alquilado en la Plazuela de San Miguel que con el tiempo se transformará en Instituto Religioso, conocido como de las Monjas Oblatas, con el fin de perfeccionar y santificar a las religiosas y a las jóvenes sirvientas acogidas en su casa. En 1876 se aprueban las Constituciones y comienzan a abrirse sucursales en otras provincias.

Tampoco en este caso se libró de los ataques la fundadora de las Oblatas, y como muestra podemos citar la opinión de Liborio Acosta de la Torre (1875: 240) quien tras explicar que hacían las veces de madres cariñosas y que su primer objeto era el de acoger temporalmente a las infelices jóvenes que hicieron de sus cuerpos un instrumento de pecado en la prostitución o fuera de ella", al no recibir reincidentes, ni a las encintas, ni a las que se encontraban algo enfermas, añade que los resultados prácticos no se correspondía con los esfuerzos de las heroicas religiosas: "porque como tienen que salir para que entren otras viciadas, no todas encuentran trabajon.

Dentro del mundo obrero femenino, aún no existen agrupaciones de carácter político, aunque algunas mujeres sí tienen un lugar común de trabajo, como les sucede a las lavanderas en las orillas de Manzanares, que conseguirán, por mediación de la esposa del rey don Amadeo, que se abra una residencia donde permanecen sus hijos mientras trabajan, y que más tarde se convertirá en Asilo para sus huérfanos. Ya en los años 80 inician sus reivindicaciones las cigarreras de la Fábrica de Tabacos con las huelgas de 1888 y 1889 , cuando se amotinan más de tres mil mujeres por las condiciones impuestas de trabajo a destajo con una materia prima de pésima calidad.

Por fortuna el nuevo siglo permitiría ya integrarse a las mujeres en muchas sociedades sin necesidad de crear ramas femeninas cuando se perseguían los mismos objetivos. 


\section{APÉNDICE DOCUMENTAL}

Francmasonería femenina. Rito de adopción o de señoras (Puga 1892)

Signo de orden de las hermanas.-Poner una mano sobre otra, la derecha cogiendo ligeramente la izquierda y ambas descansando sobre el mandil.

Signo peculiar.-Poner sobre el labio superior el dedo índice de la mano izquierda y el pulgar bajo la barba, en ademán de expresar silencio.

Respuesta-Cogerse la oreja izquierda con el pulgar y el meñique de la mano derecha, dejando extendido el resto de los dedos.

Toque.-Avanzar recíprocamente la mano derecha abierta con los dedos unidos, y colocar las manos una sobre otra, por la palma.

Marcha.-No la hay en este grado.

Saludo--Estando al orden, retirar el pie derecho, dejando quieto el izquierdo e inclinando ligeramente el cuerpo. Este saludo se hace siempre que se entre, al Asia, a la América y al África.

Palabra de paso.-Eva (en hebreo Hbavah, la vida). E, según la Biblia, el nombre de la madre común.

Palabra sagrada.-Feíz, Feáx que quiere decir Academia o escuela de virtudes.

Batería.-Cinco golpes iguales.

Aclamación.-iViva! Repetido cinco veces.

Traje.-El de sociedad, y en las ceremonias, a ser posible, blanco.

Delantal.-De piel blanca, forrado y ribeteado de azul: guantes blancos.

Banda.-De cinta azul moaré, puesta de derecha a izquierda. Las Dignatarias llevan en aspa la banda, de cuyo extremo pende una joya, una llana de Oro.

Joya.-Un corazón inflamado.

Jarretera.-Alrededor del brazo izquierdo va la Jarretera de la Orden que debe ser de satén blanco, forrada de azul y con la divisa: Silencio y virtud bordada en seda azul. A los extremos pueden ponerse flequillos de oro.

Traje de los hermanos.-De frac, con guantes y corbata blanca. Los oficiales llevan las insignias de sus dignidades, y los Hermanos las de sus grados, además de una cinta azul moaré puesta en aspa, de cuyo extremo pende una joya, una escala de oro de cinco peldaños. Hay que advertir que los Hermanos usan el signo de orden del Rito masculino en vez del femenino, agregando una ligera inclinación de cabeza y cuerpo en señal de respeto. Tampoco usan el signo peculiar.

\section{BIBLIOGRAFÍA CITADA}

ACOSTA DE LA TORRE, LiBORIO. 1875. El servicio doméstico y el Centro Protector de la mujer. Obra utilísima a todos los que tengan o bayan de tener sirvientas. Madrid: R. Velasco.

ÁlVAREZ LÁZARO, P. 1985. Masonería y librepensamiento en la España de la Restauración. Madrid.

Ballarín, Pilar. 1993 "La instrucción de un modelo de utilidad doméstica", en Georges Duby y Michelle Perrot (dir.), Historia de la mujer. Madrid: Taurus.

Carta de Nuestro Santísimo Padre el Papa Pío IX a la Asociación Católica de Señoras de Madrid. 1872. Madrid: Imp. Manuel Conesa. 
La Época. Diario. Madrid.

La Estrella de los pobres. Asociación benéfica de señoras. Memorias leídas en la Junta General, celebrada el 11 de febrero de 1875. 1875. Madrid: Imp. y Lit. de N. González.

Gimeno De Flaquer, CONCEPCIÓN. 1901. La mujer intelectual. Madrid: Imp. Asilo de Huérfanos.

Memoria de los Actos de la Sección Central de Señoras de la Cruz Roja en Madrid desde su creación hasta el fin de la Guerra Civil. 1879. Pamplona: Imp. Joaquín Lorda.

Memoria leida en el Consejo de Señoras de Madrid de la Obra de la Santa Infancia por su Presidenta la Excma. Señora Condesa de Salvatierra, el día 25 de febrero de 1856. 1856. Madrid: Aguado.

NAVASCuÉs PalaCín, Pedro. 1973. Arquitectura y arquitectos madrileños del siglo XIX. Madrid: Instituto de Estudios Madrileños.

PUGA, E. C. DE. 1892. Francmasonería Femenina. Rito de adopción de Señoras creado como una rama completamente separada de la Francmasonería masculina en el Grande Oriente de España fundado en 1780. Cartilla de Primer Grado acuerdo por - (Moreto, gr. 33ํ). Escrita por superior acuerdo por ——. Madrid: Imp. Dionisio de los Ríos.

Reglamento para las Escuelas de la Asociación Católica de Señoras de Madrid. 1872. Madrid: Imp. de Pascual Conesa.

SimÓN PALMER, MARÍA DEL CARMEN. 1972. La enseñanza privada seglar de grado medio en Madrid (1820-1868). Madrid: Instituto de Estudios Madrileños.

VIDAl Galache, FloRentina. 1993. "Ser viejo en Madrid. El hospital de incurables de Jesús Nazareno y otros centros de asistencia de ancianos", Espacio, Tiempo y Forma. Historia Contemporánea, Serie V, XI.

Vidal Galache, Florentina y Benicia. 1998 "Porque Usía es condesa", Espacio, Tiempo y Forma. Historia Contemporánea, Serie V, XVI.

La Voz de la Caridad. 1874, 1875. Madrid. 